\title{
Open SESAME
}

\section{The official opening of the SESAME synchrotron in Jordan on 16 May marked an important landmark for science in the Middle East. It is also set to become the world's first solar-powered accelerator.}

In the well-known Arabic folk tale Ali Baba and the Forty Thieves the phrase "open sesame" is used to open the mouth of a cave full of treasure. Now, the long-awaited opening of the SESAME advanced light source facility in Jordan is set to unlock a treasure of scientific opportunities for researchers in the Middle East.

SESAME is an acronym for Synchrotronlight for Experimental Science and Applications in the Middle East. It is supported by member countries from the region, namely Cyprus, Egypt, Iran, Israel, Jordan, Pakistan, the Palestinian Authority and Turkey. Based in Allan, Jordan, its mission is to provide universities and research institutes in the region with an advanced light source for performing world-class research in biology, materials science, chemistry and physics.

From its origins as an ambitious idea approved by UNESCO (United Nations Educational, Scientific and Cultural Organization) 15 years ago (C. Llewellyn Smith, Nat. Photon. 9, 550-552; 2015), it has been a long and difficult path for SESAME to reach this point. Beset by funding problems and engineering challenges, including a collapsed roof, the project has triumphed against all odds and is now getting ready for its first experiments.

SESAME is a third-generation synchrotron and at its heart has a 133-m-circumference $2.5-\mathrm{GeV}$ electron storage ring (www.sesame.org.jo). The first electron beam circulated in the ring in January 2017. Work is now ongoing to ramp up the beam current from $30 \mathrm{~mA}$ to its full specification value of $400 \mathrm{~mA}$. A total of seven beamlines are planned, of which two will be ready for use later this year.

Speaking at the opening ceremony, in his last day as president of the SESAME council, Chris Llewellyn Smith said "Today sees the fulfilment of many hopes. The hope that a group of initially inexperienced young people could build SESAME and make it work - they have: three weeks ago SESAME reached its full design energy."

Llewellyn Smith had been president of the SESAME council since 2008 and was previously a director general of CERN and is currently director of Energy Research at Oxford University. At SESAME's official opening, he handed over the presidency to

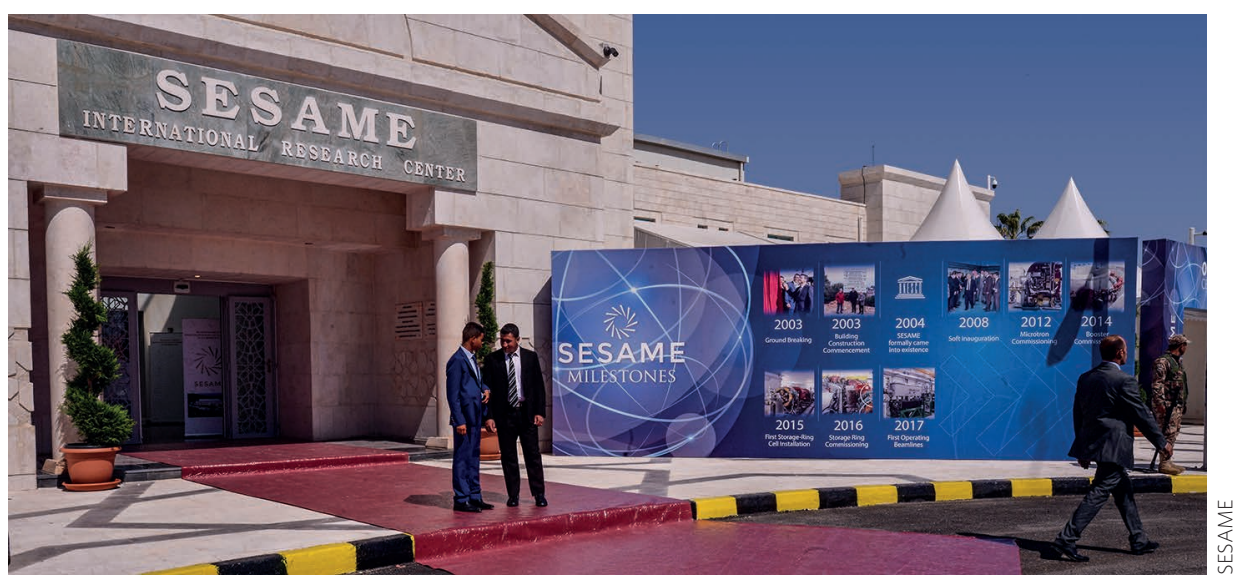

The SESAME advanced light source facility in Jordan was officially opened on 16 May 2017 by the King of Jordan, His Majesty King Abdullah II.

Rolf Heuer, also a previous director general of CERN.

"Experiments are due to begin this year with the first two beamlines," Llewellyn Smith told Nature Photonics. "The third beamline is due to start next year. The fourth in 2019. A fifth is likely to be funded by the EU [European Union]."

The first two beamlines are BASEMA (Beamline for Absorption Spectroscopy for Environment and Material Applications) and EMIRA (ElectroMagnetic Infrared RAdition). The former will support X-ray absorption and fluorescence spectroscopy, and the latter infrared microspectoscopy. The beamlines will be used for a diverse set of experiments in materials science, pollution monitoring, archaeology and biology.

The third beamline SUSAM (SESAME Users Application for Materials Science) will hopefully be online in 2018 and will perform powder diffraction experiments for materials science studies, and following that a fourth beamline for protein crystallography, an important tool for biology and pharmaceutical research, is scheduled.

Later on, beamlines five, six and seven are being planned for soft X-rays, X-ray tomography and small/wide angle X-ray scattering, funding permitting. At present, 55 proposals to use the first two beamlines have already been submitted and it is expected that the number of users will grow to 1,000 or more as more beamlines are built.
"In building SESAME, we had to overcome major financial, technological and political challenges but - with the help and encouragement of many supporters in Jordan and around the world - the staff, the directors and the council did a superb job," Khaled Toukan, the director of SESAME told attendees at the opening ceremony. "Many challenges lie ahead including building up the user community and constructing additional beamlines and supporting facilities. However, I am confident that with the help of all of you here today these challenges will be met."

Excitingly, in the long term, SESAME has ambitious plans to power the facility completely using renewable energy in the form of solar power, making it the world's first solar-powered synchrotron. This is deemed essential to make the operation of SESAME sustainable from a financial point of view as the electricity bill for running the facility ( US\$375 $\mathrm{MW}^{-1}$ ) is beyond the means of SESAME members. In late 2016, the Government of Jordan awarded SESAME with US\$7.05 million of funding to build the required solar plant and a tender for its construction has recently been issued.

It seems highly apt that SESAME held its opening on 16 May, a date that UNESCO has coincidently proclaimed to be an annual 'International Day of Light' from 2018 onwards (go.nature.com/2rgRFdQ). 